\title{
Good Or Poor Design: Comprehending Ux From An Interactive Designer Perspective, the Case of Handheld Devices
}

\author{
Guy Toko, Ernest Mnkandla
}

\begin{abstract}
The terms "system interaction", "system design", "interface development", and "GUI design" may sound different, but in reality could well mean the same thing. A computing system is a set of algorithms which are computer-readable only and which control the hardware system and are accessible via a graphical user interface (GUI), which, if poorly designed, confuses and loses users. The user-invisible algorithms are in binary format, which makes it even more difficult for ordinary users to decipher their content, since the ordinary person would rely on decimal, alphabetical, and alphanumerical representation to comprehend meaning, were they to be exposed to the inner circle of computer code. These days, GUIs are more specific than they used to be, thanks to the ingenuity of some developers, but the fight is not over yet, as new challenges are on the rise. Interaction is what stands between humans and a computing system's algorithm and provides us with information that we need in a format that humans can better understand. The reality is that, as systems are independently developed, there will be good and poor interactive design products developed by good and poor designers. Thus, here we are discussing knowing what goes on in the design room.
\end{abstract}

Keywords-User-experience, usability, interactivedesigner, inclusive-design, GUI.

\section{INTRODUCTION}

Designing and adopting any computing system in general and handheld GUI for popular use is one of the most important steps for designers, since not all users would agree or disagree on its interactivity. The approaches and views of users are as diverse as the people participating in the evaluation process; different cultures, religions, races, skill levels, experience, and the aspiration of the designer have to be considered (Yuan et al. 2015:249).

In most cases, GUI designers would take it on themselves to pass what they believe to be the most appropriate interaction onto the unsuspecting user (Yuan et al. 2015:249).

Adopting a user-centred approach enables the interactivity development team to distance themselves from all possible divisions and diversions while focusing on the "user problem" (Gelderblom 2008:67).

Revised Manuscript Received on October31, 2019

* Correspondence Author

Guy Toko*, Applies Information Systems Department of the University of Johannesbur, Johannesburg, South Africa. Email: gtoko@uj.ac.za

Ernest Mnkandla, Department of Computer Science, School of Computing, University of South Africa, Johannesburg, South Africa. Email: emnkanla@unisa.ac.za
Placing the user's needs at the centre of all preoccupations and establishing lasting solutions (Yuan et al. 2015:249), and considering the aspirations of the tangible user and not simply the type of mechanism, can be considered the driving force behind GUI interactivity and innovation (Duysburgh \& Slegers 2015:292). The aim of the user-centred approach is combining all human skills, both natural and acquired, as well as rolling out consistent usability judgement to support users rather than limiting them (Preece, Rogers \& Sharp 2002:44).

The user-centred approach takes some very important principles into consideration, which include an early focus on users and tasks, empirical measurement, and iterative design. Preece et al. (2015:327) listed the following three characteristics of the user-centred approach:

- "Early focus on users and tasks: This means first understanding who the users will be by directly studying their cognitive, behavioural, anthropomorphic, and attitudinal characteristics. This requires observing users doing their normal tasks, studying the nature of those tasks, and then involving users in the design process."

- Empirical measurement: Early in development, the reactions and performance of intended users to printed scenarios, manuals, among others, are observed and measured. Later on, users interact with simulations and prototypes and their performance and reactions are observed, recorded, and analysed.

- Iterative design: When problems are found in user testing, they are fixed and then more tests and observations are carried out to see the effects of the fixes. This means that design and development are iterative, with cycles of 'design, test, measures, and redesign' being repeated as often as necessary."

These principles of the user-centred approach, which were originally developed by Gould and Lewis (1985), seem to be widely adopted by the GUI and computing community as the basis of meaningful user-centred development. The priority seems to be on users' task aspirations and goals, and it pays close attention to users' behaviour and environment, which are the principles that highlight the priorities, preferences, and implicit user intentions (MacKenzie 2013:41). It also examines users' internal characteristics; users are consulted throughout the process of development and are invited to meetings when decisions are to be made (Preece et al. 2015:101). 


\section{Good Or Poor Design: Comprehending Ux From An Interactive Designer Perspective, the Case of Handheld Devices}

\section{LITERATURE REVIEW}

\section{1) User eXperience $(U X)$}

The UX, which is coupled with system memorability, enjoyability, learnability, and performance, is a set of individual characteristics that any system should provide its users in order to remain relevant and useful (Gelderblom 2008:97). Any interaction development team should not take this aspect lightly, as it will determine the success or failure of the entire interactive design project. Measuring the degree of UX is one of the most important aspects of system evaluation; it gives the user an overview of the system and how the user or potential user would interact with it (Rogers et al. 2013:13).

Poor or low user UX can lead to sudden abandonment and self-resistance if no timeous correction is made. Developers and interactive designers should pay close attention to these critical UX aspects (Petta, Pelachaud \& Cowie 2011:14). The assessment of the UX is not conducted with the completion of the interactivities only, nor at an early phase, but rather throughout the process of system development, in order to enable corrective measures to be taken while the product is still under development (Rosson \& Carroll 2002:50).

\section{2) Good and poor design}

Can any user, designer, or tester, when asked to conduct a GUI usability assessment, uncover any form of poor design without an HCI test instrument? Just as we may have poor systems users, can we also have poor systems interaction designers or developers? The answer is yes; just as there are good designers, there are also poor designers. An interaction design is seen as poor when users have difficulty using it, and is seen as good when users find it easy to interact with (Lazar et al. 2010).

As much as it may be hard to identify good designs, it is also difficult to identify poor designs and sometimes it takes a professional opinion to do so (Allber 1993:73). Design appreciation is dependent on an individual's taste and aspiration, and what may be perceived as poor design by some could be seen as good work by others (Lazar 2007:258). In terms of system interaction development, the absence of interaction design universality leaves room for varying interpretation and analyses, but the reality is that, when ordinary users are unable to control and use an interactive product, the design team is to blame (Lazar 2007:74). For a good interactive design, under no circumstances should users have to struggle, constantly explore, memorise steps, ask for help when navigating, question task positions, and not enjoy the process (Lazar 2007:74). Poor interaction design discourages continued usage, frustrates the user, limits interactivity, develops user resentment, and discontinues interaction. It is therefore advised that an in-depth assessment be conductedbefore any system is released to the public (Lazar 2007:75).

\section{3) Usability: Role and responsibility}

Computing system usability in the broadest sense refers to the ability to effectively and efficiently use any computing system or equipment that requires human interaction or any other third-party equipmentin order to provide or receive instructions which are needed for the successful completion of the machine's intended operation (Dermody \&Farren 2015:499). Computing systems usability is very important during all the stages of system development and is taken very seriously, since it may determine if the final system or product can be used or not, or if it will be accepted or rejected by the intended users (Dermody \&Farren 2015:499).

A general perception of the public is that system usability and friendliness are only meant to explore the interaction between humans and machines. This is not entirely accurate, since it also considers how some devices interact with thirdparty computing devices of the same or different nature with the aim of achieving a particular goal (Dermody \&Farren 2015:499). The most remarkable example of the interaction between two distinctive computing devices is an independent monitor screen and a laptop system. The two devices need each other in order to fully function. All computing operations are done on the system unit housing the processor and the other interactive unit, while the displaying role is confined to the display screen (Lee et al. 2015:607).

This specific research study focuses particularly on a section of the human usability of computing systems, and more specifically on systems usability, i.e. how a handheld computing system is particularly used by a certain group of the population (Lee et al. 2015:607). Some users are fast learners, while others are rather slow but can still retain instructions. The purpose of testing one's usability skillsmay not be to see whether or not someone may easily complete a task within a specific period, but rather how long it may take a user to adapt to the particular computing system and use it with ease (Lee et al. 2015:607). The ability to master any new utility instrument lies in the user's ability; one may look at the physical aspect, psychological state, and the age group of the user (Heinicke et al. 2015:514).

Further exploration of the physical aspects may lead to how the device is developed, its size, and the exterior appearance of the device. The aesthetic aspect of the device is one of the contributing factors that may hinder the adoption of any computing system (Heinicke et al. 2015:514). On the psychological side, the ability of any user to adopt a device lies with the current state of mind, i.e. what the user is thinking at the time. This aspect is well outside the scope of this project but one may list factors such as how the user feels at the time, or the cognitive psychology of the user, and all types of technological intimidation that may influence the user during the learning process (Heinicke et al. 2015:514). Regarding the age group aspect and the impact that it may have on the whole process, it is important to note that this is one of the most important factors that play a very important part in terms of computing systems. Nowadays, younger people find it easier to adapt to new technology than adults. The younger the user group, the better their ability to adapt to and adopt the new computing device (Heinicke et al. 2015:514). Usability skills are not as simple as the ability to move the cursor from one corner of the screen to the opposite corner, but rather a continuous inner ability to effectively and efficiently control or use a computing system. This involves many other aspects, such as visual clarity, feedback, familiarity, looks, navigation, feelings, consistency, error prevention, empathy, and efficiency (Albert et al. 2010:47). As the world is constantly discovering new electro-machinery that requires human interaction, new terms are also emerging to describe how they must be developed in order to fast-track adaptation and adoption. 
One of these terms is universal usability, which describes usage steps that are generic enough to allow anyone to manipulate a system without having to spend a considerable amount of time learning procedures, as relying on intuition to complete the tasks at hand can be useful (Al-Megren et al. 2015:78).

Other schools of thought simply describe universal usability as good plain design; in other words, interface design that is simple and easy to work with, and interactive design that is based on natural human metaphors and easily made to enable its user to constantly create the link with its closed atmosphere (Ballmer 2010:38). Although the most simplistic and accommodating approach is to describe usability simply as good plain design, can we merely call it that? That rejoinder may come from the statement that system usability comes with more sub-aspects and that simply developing a perfect GUI during the development stage is widely debatable (Ghosh \& Pherwani 2015:529). The usabilityrelated aspects of any computing system's GUI or interaction require considerable research time during all phases of growth and is a never-ending cycle (Ghosh \& Pherwani 2015:529). The importance of usability is entrenched in computing systems' GUI development that designers need to consistently pay attention to. This includes components such as learnability, which is the user's ability to explore, and how easy it may be for any first-time user to complete a particular process and repeat it without having to learn it all over again (Ghosh \& Pherwani 2015:529). Efficiency, on the other hand, explores the action of any user to determine if they can accomplish the task they initially intended to accomplish (Ghosh \& Pherwani 2015:528).

Memorability plays a very important role regarding systems usability. It examines the process to determine if the user should recall all the steps all of the time, or if, after being away from the GUI system for some time, they would be over again (Mayas et al. 2015:537). Errors or erroneous processes, which deal with how often users make mistakes (once or consistently), how often they repeat these errors, and the severity of those errors, are all part of memorability (Mayas et al. 2015:537). Regarding system usability and especially interaction design, a designer always needs to consider the following ten heuristics, which include the visibility of system status. The question is whether the handheld system always keeps its users informed about what is happening or whether it provides feedback when needed (Nielsen 1995:170). Does the handheld interaction artefact match the real world? Does the computer interact with real users or people who live in their natural environment or does the system for some reason speak their language or use acceptable language deviation, and use their concepts? (Mubin, Mahmud \& Shahis 2015:542).

\section{RESEARCH QUESTION}

Good or poor interactive design: how UX interactive designers see UX from their perspective?

\section{RESEARCH METHODOLOGY}

Although part of a major search project, this paper is based on a qualitative research method only. The researcher approached a number of interactive designers, mostly people who are still active in the field of computing and requested able to complete the sametasks without complications all

to hear their side of the story. Survey questions were sent to them via email and after completion were sent back to the researcher for analysis. The researcher later integrated all the responses collected into the main study for data analysis. No automated data analysis was used here but we conducted all the interpretation using traditional qualitative data analysis through quotes to conclude our analysis.

\section{Population Of SAMPle}

We invited around 95 active interactive designers from around the Republic of South Africa, people who are currently involved in some form of handheld interactive design, GUI design, application development or as an assessor. The main objective was to only speak to those who are actively working in the field. We had a positive response from 39 designers and 32 participated or gave us some form of response.

\section{COUNTRY WHERE THE RESEARCH WAS CONDUCTED}

The study was conducted only in the Republic of South Africa, and most, if not all, respondents were located in the country or worked on local projects.

\section{RESEARCH LIMITATION AND GOAL}

The main goal of this article is to explore the mindset of GUI interactive producers to hear their opinions and understand what goes on behind closed doors. This investigative article target is limited to IT specialists who have GUI development as their main duties. The article is part of a much bigger research project which covers a larger aspect of human-computer interaction. The data which are presented here were collected as part of that bigger project. Questions were put to various developers around the country and analysed qualitatively, as shown here.

\section{VIII.DATA ANALYSIS}

\section{A. Data Interpretation}

Some of the major themes from respondents were as follows: during the initial phase of the development process; previewing user frustration during the development process; and before the release of the product.

The above statements from respondents mean the following:

- Early testing phases of the interaction

- $\quad$ Testing user frustration during the overall testing process only

- Before releasing the final product to the public

- Testing user frustration during the overall assessment

Based on the meaning of what the respondents indicated above, one may ask oneself, what can be done to achieve the above?

It appears as if most interactive developers are not well aware of the importance of assessing the level of user frustration regarding the quality of any computing system. 


\section{Good Or Poor Design: Comprehending Ux From An Interactive Designer Perspective, the Case of Handheld Devices}

In some instances, it seems to be integrated into the overall systems testing, or not having the attention it may deserve. the impact user frustration may have on any computing user. It is thus important to have an independent set of assessment tools to measure the level of user frustration during all Response 5, "User frustration is the leading cause of abandonment regarding computing systems and other related products, and therefore we need to be aware of that when designing user interaction in general and particularly usability and navigation." Taking users' level of frustration into account during a usability assessment may have a positive impact, as indicated in Table 1.

This question was about understanding how a developing team approaches the issue of user frustration at the developmental stage. The answers varied widely. Some indicated that they conducted a pilot assessment to overcome the user frustration that may be attached to the usability of the device, while others indicated that they often included the user in all stages of system development, which enabled them to constantly assess the degree of user frustration and address it while they still could. It appears that all respondents were of the view that any form of user frustration needs to be dealt with as soon as possible.

\section{B. Data Interpretation}

In the above table, the respondents indicated that user needs were central, leading to user-friendliness and US. Issues such as user-friendliness and US were some of the keywords in the respondents' answers. From the responses, one can conclude the following:

- The systems must afford ease of use.

- The interface must be visually pleasing.

- The use of familiar icons is important.

- The size and label of icons must be clear enough for everyone.

- System instructions must be easy to understand.

- The interoperability of all platforms must be guaranteed.

- The systems must support users' needs.

Next, we need to examine what is required to achieve the above set of preferences.

Some of the key phrases in the responses include design seems to be globalising all the above; through design, standard processes can be achieved, which takes into account the users' needs and aspirations; and the use of good and familiar graphics and having the most reliable set of system requirements are the key to deliver and address the understanding of users' needs.

Based on the above, one response (Number 1) indicated that "they make it user friendly" to a greater extent, which means that by fully integrating user-friendliness into the system's development, one may understand users' needs.

The ICT professionals believe that it is very important to put users' needs at the centre of any form of design. Some believe that no success can be achieved unless users' needs are placed at the centre of the design. In order to make interactive designs more user friendly, it is very important that application icons should be familiar to the user. Some believe that designing a GUI is more stressful than any other design task, as designers always need to ensure they reassess their priorities at all times. To achieve the above, one needs to assess and acknowledge phases of the system-development life-cycle. As indicated in

\section{Data Interpretation}

From the above answers, the researcher identified summative themes such as guideline, disaster prevention, and unacceptable lack of consistencies. This generally means the following:

- A means of guiding the overall design process.

- A mechanism that prevents losing control over the aim of design interactivity.

- Having it as a priority helps to control and prevent errors.

Based on the above, and having explored the overall meaning of those themes, it can be concluded that, in order to address the question in Table 3 , one needs to develop system prototypes that portray the needs and aspirations of both the designers and users by paying close attention to design issues, such as the navigation and flow of handheld systems, the order of processing during interaction, and maintaining a close sense of consistency when designing an interaction. As Respondent 5 indicated in Table 3, "Any important interaction design must always be consistent with an agreed process; otherwise it would not help the project." From the output presented here, most respondents agreed that design consistencies constitute an important element that guides their overall approach for development. Design consistencies are mostly used as an approach in which the design team uses similar operations and similar elements for developing similar tasks, operations, processes, and pages. This rule has to be applied consistently and broadly to enable the user to easily identify similar operations based on previous experience. Some indicated that they do apply them as broadly as they can in order to prevent any form of confusion and promote easy memorability of the system.

\section{Data Interpretation}

From these responses, the researcher identified the following key phrases: the inclusion of artefacts such as an application wizard into the operating system and paying great attention to the needs of first-time users.

From the above, one can conclude that the respondents meant the following:

- The inclusion of an application that can guide firsttime users

- First-time users' needs.

- Paying attention to first-time users

- Making first-time users a priority

- Simply ignoring first-time users may not make sense

This brings us to system analysis and design. Comprehending users' needs is just part of the process of elicitation; therefore better comprehension of the needs of users is essential. The specific needs of first-time users may not be part of set priorities, but, based on the responses, it seems to play a major role in the accomplishment of using a handheld computing system.

In Response 2 in Table 4, interactive developers acknowledged their role and responsibility regarding guiding any first-time user. 
Judging by the responses in Table 4, users are treated as a group. At first it may sound as if little consideration is given to individual segments of the user community and most attention is directed towards providing an ultimate solution, which may be ideal for any ordinary user; however, some designers indicated that in their approaches they consider the issue of a first-time user as part of their wider integration, and they explore the interaction regarding the various versions that they intend to release. In most cases, the designers start with the initial version, which is more user friendly, and later release a more advanced version. They tend to increase the usability burden and sophistication.

\section{E. Data Interpretation}

This question was aimed at knowing what impact user experience and emotions had on interactive designers when working on interaction. From the above responses, the researcher identified a few common keywords which may assist in generalising their responses, namely, testing and validation of user emotion; creating an emotional link with users; and verifying due processes.

Based on the above statements, the respondents referred to the following:

- Capturing user emotion and dealing with them while possible

- Testing user emotion before any release

- Measuring the level of user emotion before releasing it

- Understanding the degree of user engagement and emotion when designing

- Assessing the final product before releasing it

The researcher believes that the above can be achieved by progressively reviewing and evaluating user interaction and addressing shortfalls as soon as they are identified. The computing users in general developed and maintained some form of emotional connection with their devices, and, most importantly, new users or adult first-time users were prone to some forms of emotional distress if they were unable to control the systems the way they intended to. As indicated by Respondent 8 , "Customer experience is what makes any product what it is. Customers are the users, and if users are not okay, then the product is useless; and from the emotion side of it, if the emotions of the user are not considered during the design process, the entire project can be in a poor state."

Regarding the roles that assessing the user experience and user emotions may play, many respondents were adamant that it constituted the key evaluation that each needed to comply with in order to be commercialised. According to the responses, the ultimate hurdle that all interactivity design processes must meet is using active participant users who can assess the system interactivities and measuring their responses to the task being tested, and only when successfully completed, can the next process be initiated.

They believed that testing and ensuring that the system is enjoyable for its users should be met. From the above, one may simply conclude that many participants, as the result of facing many layers of frustration with the systems, felt that their needs were not taken into consideration, which contradicts the responses in Table 5.

\section{F. Data Interpretation}

To the above question, there were multiple repetitive answers which contained the following themes: developers must conduct frequent testing, and they must develop comprehensive handheld usability instructions, such as graphical and text assistance.

By these responses, the respondents are referring to:

- clear user instructions

- demo videos

- $\quad$ step-by-step procedures

- simplified user experience

- developing tutorial materials

- having systems that cater for both experienced and non-experienced users

- Avoiding the introduction of totally new systems. The above can be achieved as follows:

It is very clear that having a good set of user requirements obtained during the elicitation process can easily shed light on some of the issues experienced by adult first-time users. It appears as if their needs are not well understood from the onset, or from the time the development process was initiated. It also appears essential that developing and releasing a comprehensive user training material may also assist in addressing the usability issues of adult first-time users. It is also important to progressively introduce new system features to enable slow learners to adapt easily.

Computing systems development and interactive systems development for South African users may not be as simple as one may want it to be because these systems are often developed in other regions of the world where the same social dimensions do not apply. One needs to be constantly reminded of what other consumers may be dealing with, as stated by Respondent 17: "The GUI doesn't undergo huge changes with every new model. Every model is built so that new users can easily understand and use the tablet easily." When the pace of systems development is too fast, some users get lost or confused in the process.

The best way to do so is to assess the needs of the users at the beginning of the design, to explore all avenues to fully understand the users' needs, and to spend sufficient time reassessing their priorities. While respecting HCI principles in this manner, one may easily master what their needs are and address them in the most comprehensive manner.

\section{CONCLUSION}

The summary of each set of data presented above is a better representation of the outcomes of the study and from all the six tables, we have observed that participants gave some valuable insight that can contribute towards the understanding of what goes on in the developer's corner when no one is observing. Issues such as the evaluation of the level of users' frustration, the testing of various levels to ascertain the degree of acceptance are just some of the answers we have identified. From Table 2, we have seen issues such as ease of use, interface design, the type of icon selected, the size of label, and the type of instruction are just some of answers we are getting. From Table 4, some respondent is making reference about inclusivity, such as the need of senior citizens. In Table 5, the issue of emotion is addressed, what is one of the critical aspects of usability, and here developers are to some extent paying attention to it. 


\section{Good Or Poor Design: Comprehending Ux From An Interactive Designer Perspective, the Case of Handheld Devices}

The study took us through the process of comprehending and understanding the technicality of designing or developing some interactive systems by taking into account various aspects of UX, exploring what may appear as poor or good design and giving us some valuable answers.

\section{REFERENCES}

1. Allber, AF. 1993. Interactive Computer Systems. 1st edition. New York: Plenum Press

2. Albert, B, Tullis, T \& Tedesco, D. 2010. Beyond the Usability Lab, Conducting Large-scale Online User Experience Studies. 1st edition. Burlington: Elsevier.

3. Al-Megren, A, Kharrufa, A, Hook, J, Holden, A, Sutton, S \& Olivier, P. 2015. Comparing fatigue when using large horizontal and vertical multi-touch interaction displays. Lecture Notes in Computer Science, 9299:156-164.

4. Akamatsu, S, Yoshida, M \& Satoch, H. 2015. Interactive check system for facilitating self-awareness of dorm students in upper secondary education. Lecture Notes in Computer Science, 9299:569573.

5. Ballmer, S. 2010. A transforming trend - The natural user interface.Available at: www.huffingtonpost.com/steve-ballmer/ces2010-a-transforming-t b 416598.html (accessed on 16/12/2016).

6. Dermody, FAS \& Farren, M. 2015. Multi-modal system for public speaking: Pilot study on evaluation of real-time feedback. Lecture Notes in Computer Science, 9299:499-518.

7. Duysburgh, P \& Slegers, K. 2015. Reciprocity in rapid ethnography: Giving back by making the small things count. Interact, 2015:292299.

8. Gelderblom, JH. 2008. Designing Technology for Young Children: Guidelines Grounded in a Literature Investigation on Child Development and Children's Technology. Johannesburg: UNISA.

9. Gould, J \& Lewis, C. 1985. Designing for usability: Key principles and what designers think. Communications of the ACM 28(3):300 311.

10. Ghosh, S \& Pherwani, J. 2015. Enabling naturalness and humanness in mobile voice assistants. Lecture Notes in Computer Science, 9299:528-532.

11. Heinicke, A, Bröhl, C, Dokas, I, Walbaum, K, Bützler, J \& Schlick, C. 2015. Development of usability-criteria for the selection process of document management systems. Lecture Notes in Computer Science 9299:514-517.

12. Lazar, J, Feng, JH \& Hochheiser, H. 2010. Research Methods in Human-computer Interaction. Sussex: Wiley.

13. Lazar, J. 2007. Universal Usability: Designing Computer Interfaces for Diverse Users. Sussex: Wiley.

14. Lee, C, Lee, J \& Kim, GJ. 2015. Touch skin: Proprioceptive input for small screen devices. Lecture Notes in Computer Science, 9299:607-615.

15. MacKenzie, SI. 2013. Human-computer Interaction: An Empirical Research Perspective. 1st edition. Walthan: Elsevier.

16. Mayas, C, Hörold, S, Stelzer, A, Englert, F \& Krömker, H. 2015. Evaluation of dispatcher requirements on automated customer feedback in public transport. Lecture Notes in Computer Science, 9299:537-541.

17. Mubin, O, Mahmud, AA \& Shahis, A. 2015. Experience of teaching HCI to a multidisciplinary cohort of computer and design students. Lecture Notes in Computer Science, 9299:542-553.

18. Nielsen, J. 1995. Advances in Human/Computer Interaction: Volume 5. 1st edition. New York: Wiley.

19. Petta, P, Pelachaud, C \& Cowie, R. 2011. Emotion-oriented Systems. 1st edition. Saarbrucken: Springer.

20. Preece, J, Rogers, Y \& Sharp, H. 2002. Interaction Design: Beyond Human-computer Interaction. USA: Wiley.

21. Preece, J, Rogers, Y \& Sharp, H. 2015. Interaction Design: Beyond Human-computer Interaction. Sussex: Wiley.

22. Rogers, Y, Sharp, H \& Preece, J. 2013. Interaction Design: Beyond Human-computer Interaction. 3rd edition. Sussex: Wiley.

23. Rosson, MB \& Carroll, JM. 2002. Usability Engineering: Scenariobased Development of Human-computer Interaction (Interactive Technologies). San Francisco: Morgan Kaufmann.

24. Shahid, S \& Mubin, O. 2015. First impression matters: Exploring the mediating effect of previous experience on the perception of beauty and usability. Lecture Notes in Computer Science, 9299:555-562.

25. Tarkkanen, K, Harkke, V \& Reijonen, P. 2015. Testing the unknown - Value of usability testing for complex professional systems development. Lecture Notes in Computer Science, 9297:300-314.
26. Yuan, X, Sa, N, Begany, G \& Yang, H. 2015. What users prefer and why: A user study on effective presentation styles of opinion summarization. Lecture Notes in Computer Science, 9297:249-264. 


\begin{tabular}{|c|c|}
\hline \multicolumn{2}{|r|}{ Table 1: Qualitative question 1-GUI design perspectives } \\
\hline \multicolumn{2}{|r|}{ Question } \\
\hline \multicolumn{2}{|r|}{ From a GUI designing perspective, at what moment do you measure the level of user frustration? } \\
\hline Number & Responses \\
\hline 1 & During initial testing, yes, and after release of the product, it can be very difficult to assess. \\
\hline 2 & Yes, we do, but only during the testing situation. \\
\hline 3 & It can be helpful if we checked it before any user becomes frustrated with our product. \\
\hline 4 & $\begin{array}{l}\text { No, developers may simply ignore this call, and we need to be very aware of that by removing any hurdle that may } \\
\text { lead to that type of user frustration. }\end{array}$ \\
\hline 5 & $\begin{array}{l}\text { User frustration is the leading cause of abandonment regarding computing systems and other related products, and } \\
\text { therefore we need to be aware of that when designing user interaction in general and particularly usability and } \\
\text { navigation. }\end{array}$ \\
\hline 6 & $\begin{array}{c}\text { Yes, it is important that we verify that aspect before releasing the system. If not, it can lead to clients not using our } \\
\text { product. }\end{array}$ \\
\hline 7 & $\begin{array}{l}\text { We are aware of the phenomenon; that is the reason we always conduct user testing and analyse the level of } \\
\text { frustration from their part before releasing the final product to the public. }\end{array}$ \\
\hline 8 & It may help the developing team when testing their final version of the product as the users. \\
\hline
\end{tabular}

\begin{tabular}{|c|c|}
\hline \multicolumn{2}{|r|}{ Table 2: Qualitative question 2 - Usability and accountability } \\
\hline \multicolumn{2}{|r|}{ Question } \\
\hline \multicolumn{2}{|r|}{ How are the needs of users taken into account when designing the GUI? } \\
\hline Number & Response \\
\hline 1 & They make it user friendly. \\
\hline 2 & $\begin{array}{l}\text { The use of applicable icons and organising the menu by grouping related features under same categories help the user } \\
\text { to easily get accustomed to the graphical user interface. }\end{array}$ \\
\hline 3 & $\begin{array}{l}\text { One method that manufacturers use to cater for both new and experienced users is by having a variety of handheld } \\
\text { devices where users can choose the one that best caters for their needs. Another way is by keeping the interface } \\
\text { standard. }\end{array}$ \\
\hline 4 & They design similar graphic user interfaces. \\
\hline 5 & $\begin{array}{l}\text { I think they are taken into account quite well, because tablet systems are user friendly; one would not have troubles } \\
\text { trying to figure out or locate a certain feature. }\end{array}$ \\
\hline 6 & The GUI should be user friendly. \\
\hline 7 & $\begin{array}{l}\text { Their needs are taken into account in the fact that GUI devices can interact with multiple devices such as MP3 } \\
\text { portable media players, gaming devices, and smaller household, office, and industrial equipment. Also, it can be } \\
\text { manipulated with a mouse and by some extent a keyboard. }\end{array}$ \\
\hline 8 & $\begin{array}{l}\text { Brightly coloured and widely used icons that are consistent throughout devices help users use their tablets but there is } \\
\text { still much to do in this regard. }\end{array}$ \\
\hline 9 & Manufactures put the end user first. \\
\hline 10 & They ask employees within the company how they would like it to be (survey). \\
\hline
\end{tabular}


Good Or Poor Design: Comprehending Ux From An Interactive Designer Perspective, the Case of Handheld Devices

\begin{tabular}{||c|c||}
\hline \multicolumn{2}{|c|}{ Table 3: Qualitative question 3-Design consistencies } \\
\hline \multicolumn{2}{|c||}{ Question } \\
\hline Number & Rrom your own experience, what is the importance of design consistencies? \\
\hline 1 & In any serious development project, we remain consistent. \\
\hline 2 & Consistency helps everyone, as it guides our overall designs. \\
\hline 3 & Very important when doing projects like GUI. \\
\hline 4 & Without that, it could be a disaster to all. \\
\hline 5 & Any important interaction design must always be consistent with an agreed process; otherwise it would not help the \\
\hline 6 & project. \\
\hline 7 & Thack of consistencies in any design project is bad and totally unacceptable. \\
\hline 8 & To keep our project relevant, we must be consistent. \\
\hline 9 &
\end{tabular}

\begin{tabular}{|c|c||}
\hline \multicolumn{2}{|c|}{ Table 4: Qualitative question 4-Interactive designing } \\
\hline \multicolumn{2}{|c|}{ Question } \\
\hline From an interactive and designing perspective, what mechanism enables you to guide any first-time user of a tablet system? \\
\hline 1 & $\begin{array}{c}\text { From our developmental approach, we include an application wizard into our product, which can easily guide the } \\
\text { developmental process of any first-time user. Of course we pay great attention to first-timer user needs and anyone } \\
\text { that can be classified as such. }\end{array}$ \\
\hline 2 & We may not be able to cater for all options, but we pay great attention to any first-time user. \\
\hline 3 & That should be our priority. \\
\hline 4 & It may not make sense if we simply ignore them. \\
\hline 5 & Yes, we include user needs. \\
\hline 6 & \\
\hline
\end{tabular}




\begin{tabular}{|c|c|}
\hline \multicolumn{2}{|r|}{ Table 5: Qualitative question $5-U X$ and emotion } \\
\hline \multicolumn{2}{|r|}{ Question } \\
\hline \multicolumn{2}{|r|}{ What impact does "user experience" and "emotion" have when designing interaction? } \\
\hline Number & Responses \\
\hline 1 & $\begin{array}{c}\text { User experience is what makes the whole testing process worth something, and user emotion is captured on camera } \\
\text { and then analysed afterwards. }\end{array}$ \\
\hline 2 & We are using these two aspects to check our products. \\
\hline 3 & User experience and emotion are also tested and validated by the designing team. \\
\hline 4 & $\begin{array}{l}\text { We have our own internal standard when measuring user experience and level of emotion when they deal with our } \\
\text { product. It is important to know how people/users feel about our product and the level of emotional connection with } \\
\text { the interaction development during testing processes. }\end{array}$ \\
\hline 5 & Yes, we also explore that aspect when development is taking place. \\
\hline 6 & Yes, we do test that as well. \\
\hline 7 & It helps to verify that process before moving the release of the final system. \\
\hline 8 & $\begin{array}{l}\text { Customer experience is what makes any product what it is. Customers are the users, and if users are not okay, then the } \\
\text { product is useless; and from the emotion side of it, if the emotions of the user are not considered during the design } \\
\text { process, the entire project can be in a poor state. }\end{array}$ \\
\hline
\end{tabular}

\begin{tabular}{|c|c|}
\hline \multicolumn{2}{|r|}{ Table 6: Qualitative question 6-Design processes } \\
\hline \multicolumn{2}{|r|}{ Question } \\
\hline \multicolumn{2}{|r|}{ During the design process, how do you cater for both experienced and first-time adult users? } \\
\hline Number & Responses \\
\hline 1 & Instructions at the beginning of each device when it is being switched on for the first time. \\
\hline 2 & Instructions on the package. \\
\hline 3 & I don't know what it meant by user friendly. \\
\hline 4 & $\begin{array}{l}\text { They make sure that there is a demo video that comes with the device. What it basically entails is the step-by-step } \\
\text { procedures of performing tasks. }\end{array}$ \\
\hline 5 & Manual instructions and software can be used to cater for all. \\
\hline 6 & They make sure that the user experience becomes simple enough for anyone to grasp. \\
\hline 7 & $\begin{array}{c}\text { They cater by introducing new technologies and for the first time there are tutorials to help them understand the } \\
\text { features. }\end{array}$ \\
\hline 8 & They create multiple devices for experts and novices. \\
\hline 9 & By having cheaper and simpler tablets. \\
\hline 10 & $\begin{array}{c}\text { For the experienced, by improving the performance and the quality of the devices; and for the first-time users, by } \\
\text { providing some much-needed help through tutorials or simplified software. }\end{array}$ \\
\hline
\end{tabular}

